\title{
Inflammatory Bowel Disease and COVID-19
}

\author{
Sulmaz Ghahramani ${ }^{1}$, Marjan Roozitalab ${ }^{2}$, Zahra Gholami ${ }^{1}$ and Kamran Bagheri Lankarani ${ }^{1}{ }^{*}$ \\ ${ }^{1}$ Health Policy Research Center, Institute of Health, School of Medicine, Shiraz University of Medical Sciences, Shiraz, Iran \\ ${ }^{2}$ Clinical Affairs, Shiraz University of Medical Sciences, Shiraz, Iran \\ "Corresponding author: Health Policy Research Center, Institute of Health, School of Medicine, Shiraz University of Medical Sciences, Building No 2, Eighth Floor, Zand Ave, \\ Shiraz, Iran. Tel/Fax:+ 98-7132309615, Email: lankaran@sums.ac.ir
}

Received 2020 June 15; Accepted 2020 June 16.

Keywords: Inflammatory Bowel Disease, Shiraz, COVID-19

\section{Dear Editor,}

SARS-CoV-2, a novel virus causing COVID-19 in addition to respiratory symptoms $(1,2)$, may present with gastrointestinal symptoms, including diarrhea (3-5), even without respiratory complaints (6).

This virus is severe in people with underlying diseases, including diabetes and cardiovascular disease, and those with cancer (1). There are controversial reports on the course of infection in people on immunosuppressive drugs (7-10).

Care of patients affected with inflammatory bowel disease (IBD) might be challenging during the current pandemic of SARS-CoV-2. IBD is a chronic disease characterized by exacerbations and remission, which may mandate the use of immunosuppressive treatment for control. Immunosuppressive medications are known to be a risk factor for viral infection (11). The exacerbation of disease needs to be distinguished from infection with the novel virus, while the use of immunosuppressive may affect the course of COVID-19.

To date, there are limited reports of IBD patients affected by COVID-19 (12-14). Here, we reported our experience in the care of these patients during the current pandemic.

The IBD outpatient clinic at the Faghihi Hospital affiliated to the Shiraz University of Medical Sciences, Shiraz, Iran, represents one of the largest referral clinics of IBD patients in the country. This clinic provided diagnostic, therapeutic, and maintenance follow up of IBD patients regularly before the epidemics of COVID-19 in Iran in February 2020. However, activities of the clinic were affected immediately after the disease. We promptly implemented an active strategy of phone call screenings and provided patients with medical consultation and healthpromoting messages. Counseling services and quick re- sponses through telematic tools were provided via social media, including Instagram and WhatsApp. This was a volunteered activity by physicians and nurses working at the clinic without being funded. Counseling services were voluntarily performed by a trained Inflammatory bowel disease (IBD) nurse, community medicine, and GI specialist. Up to June 4, 2020, around 300 registered IBD patients were telephoned, and 100 of them responded. The mean ( \pm standard deviation) age of the respondents was $39.7 \pm$ 15 , and $62 \%$ were female. Most of the patients (83\%) had ulcerative colitis, and three women were pregnant. Onefourth $(25 \%)$ of the patients were receiving glucocorticosteroids in different doses, $5 \%$ were receiving immunomodulators, mainly azathioprine, and $14 \%$ were receiving biologics, including Adalimumab or Infliximab. Twenty patients reported that they discontinued at least one of their medications in the last two months.

We found no IBD patients affected by COVID-19 in this group (0/100). During the same period, 6397 people were found to be infected with SARS-CoV-2 in Fars Province, Iran, and 113 related deaths were reported.

In concordance with other available evidence, this study indicated that IBD patients did not show any increased risk of COVID-19 infection (15-18). This might be related to high health literacy among these patients with chronic diseases and the appropriate information we provided to prevent the infection. These findings do not negate the published recommendations for infection prevention and IBD management during the COVID-19 pandemic $(19,20)$. Since the information about COVID-19 is rapidly changing on a daily basis, further large-scale investigations on IBD patients are urgently needed. 


\section{Footnotes}

Authors' Contribution: KBL and SG developed the original idea. ZG and MR contributed to the data collection and data cleaning. KBL and SG abstracted and analyzed the data. All the authors contributed to writing the manuscript and approved its final version.

Conflict of Interests: All the authors declare that there is no conflict of interest regarding the publication of the study.

Funding/Support: The authors received no funding support for this study.

\section{References}

1. Rodriguez-Morales AJ, Cardona-Ospina JA, Gutierrez-Ocampo E, Villamizar-Pena R, Holguin-Rivera Y, Escalera-Antezana JP, et al. Clinical, laboratory and imaging features of COVID-19: A systematic review and meta-analysis. Travel Med Infect Dis. 2020;34:101623. doi: 10.1016/j.tmaid.2020.101623. [PubMed: 32179124]. [PubMed Central: PMC7102608]

2. Sun P, Qie S, Liu Z, Ren J, Li K, Xi J. Clinical characteristics of hospitalized patients with SARS-CoV-2 infection: A single arm meta-analysis. J Med Virol. 2020;92(6):612-7. doi: 10.1002/jmv.25735. [PubMed: 32108351]. [PubMed Central: PMC7228255].

3. Pan L, Mu M, Yang P, Sun Y, Wang R, Yan J, et al. Clinical characteristics of COVID-19 patients with digestive symptoms in Hubei, China: A descriptive, cross-sectional, multicenter study. Am J Gastroenterol. 2020;115(5):766-73. doi:10.14309/ajg.0000000000000620. [PubMed: 32287140]. [PubMed Central: PMC7172492].

4. Tian Y, Rong L, Nian W, He Y. Review article: Gastrointestinal features in COVID-19 and the possibility of faecal transmission. Aliment Pharmacol Ther. 2020;51(9):843-51. doi:10.1111/apt.15731. [PubMed: 32222988]. [PubMed Central: PMC7161803].

5. Cheung KS, Hung IFN, Chan PPY, Lung KC, Tso E, Liu R, et al. Gastrointestinal manifestations of SARS-CoV-2 infection and virus load in fecal samples from a Hong Kong cohort: Systematic review and metaanalysis. Gastroenterology. 2020. doi: 10.1053/j.gastro.2020.03.065. [PubMed: 32251668]. [PubMed Central: PMC7194936].

6. Remes-Troche JM, Ramos-de-la-Medina A, Manriquez-Reyes $M$, Martinez-Perez-Maldonado L, Lara EL, Solis-Gonzalez MA. Initial gastrointestinal manifestations in patients with SARS-CoV-2 in 112 patients from Veracruz (Southeastern Mexico). Gastroenterology. 2020. doi: 10.1053/j.gastro.2020.05.055. [PubMed: 32446696]. [PubMed Central: PMC7241401].

7. Zhu L, Xu X, Ma K, Yang J, Guan H, Chen S, et al. Successful recovery of COVID-19 pneumonia in a renal transplant recipient with longterm immunosuppression. Am J Transplant. 2020;20(7):1859-63. doi: 10.1111/ajt.15869. [PubMed: 32181990]. [PubMed Central: PMC7228349].

8. Novi G, Mikulska M, Briano F, Toscanini F, Tazza F, Uccelli A, et al. COVID-19 in a MS patient treated with ocrelizumab: Does immunosuppression have a protective role? Mult Scler Relat Disord. 2020;42:102120. doi: 10.1016/j.msard.2020.102120. [PubMed: 32315980]. [PubMed Central: PMC7156942].

9. Huang J, Lin H, Wu Y, Fang Y, Kumar R, Chen G, et al. COVID-19 in posttransplant patients-report of 2 cases. Am JTransplant. 2020;20(7):187981. doi: 10.1111/ajt.15896. [PubMed: 32243697].

10. Conforti C, Giuffrida R, Dianzani C, Di Meo N, Zalaudek I. COVID-19 and psoriasis: Is it time to limit treatment with immunosuppressants? A call for action. Dermatol Ther. 2020. e13298. doi: 10.1111/dth.13298. [PubMed: 32157783]. [PubMed Central: PMC7228204].

11. Kirchgesner J, Lemaitre M, Carrat F, Zureik M, Carbonnel F, DraySpira R. Risk of serious and opportunistic infections associated with treatment of inflammatory bowel diseases. Gastroenterology. 2018;155(2):337-346 e10. doi: 10.1053/j.gastro.2018.04.012. [PubMed: 29655835].

12. Mazza S, Sorce A, Peyvandi F, Vecchi M, Caprioli F. A fatal case of COVID 19 pneumonia occurring in a patient with severe acute ulcerative colitis. Gut. 2020;69(6):1148-9. doi: 10.1136/gutjnl-2020-321183. [PubMed: 32245909].

13. Bezzio C, Saibeni S, Variola A, Allocca M, Massari A, Gerardi V, et al. Outcomes of COVID-19 in 79 patients with IBD in Italy: An IG-IBD study. Gut. 2020;69(7):1213-7. doi:10.1136/gutjnl-2020-321411. [PubMed: 32354990]. [PubMed Central: PMC7242872].

14. Tursi A, Papa A. Impact of anti-tnfalpha antibodies on the risk of Covid-19 and its severity in patients with inflammatory Bowel Diseases. J Crohns Colitis. 2020. doi: 10.1093/ecco-jcc/jjaa076. [PubMed: 32303756]. [PubMed Central: PMC7188162].

15. Mao R, Liang J, Shen J, Ghosh S, Zhu LR, Yang H, et al. Implications of COVID-19 for patients with pre-existing digestive diseases. Lancet Gastroenterol Hepatol. 2020;5(5):425-7. doi: 10.1016/S2468-1253(20)300765. [PubMed: 32171057]. [PubMed Central: PMC7103943].

16. Norsa L, Indriolo A, Sansotta N, Cosimo P, Greco S, D’Antiga L. Uneventful course in patients with inflammatory bowel disease during the severe acute respiratory syndrome coronavirus 2 outbreak in Northern Italy. Gastroenterology. 2020. doi: 10.1053/j.gastro.2020.03.062. [PubMed: 32247695]. [PubMed Central: PMC7270273].

17. An P, Ji M, Ren H, Su J, Kang J, Yin A, et al. Protection of 318 inflammatory bowel disease patients from the outbreak and rapid spread of COVID-19 infection in Wuhan, China. SSRN Electron J. 2020. doi: 10.2139/ssrn.3543590.

18. Al-Ani AH, Prentice RE, Rentsch CA, Johnson D, Ardalan Z, Heerasing $\mathrm{N}$, et al. Review article: Prevention, diagnosis and management of COVID-19 in the IBD patient. Aliment Pharmacol Ther. 2020;52(1):5472. doi: 10.1111/apt.15779. [PubMed: 32348598]. [PubMed Central: PMC7267115]

19. Rubin DT, Feuerstein JD, Wang AY, Cohen RD. AGA clinical practice update on management of inflammatory Bowel disease during the COVID-19 pandemic: Expert commentary. Gastroenterology. 2020. doi: 10.1053/j.gastro.2020.04.012. [PubMed: 32283100]. [PubMed Central: PMC7151253].

20. Kennedy NA, Jones GR, Lamb CA, Appleby R, Arnott I, Beattie RM et al. British Society of Gastroenterology guidance for management of inflammatory bowel disease during the COVID-19 pandemic. Gut. 2020;69(6):984-90. doi: 10.1136/gutjnl-2020-321244. [PubMed: 32303607]. [PubMed Central: PMC7211081]. 